OPEN ACCESS

Edited by: $\mathrm{Jie} \mathrm{Hu}$,

The Ohio State University, United States

Reviewed by: Raheem Paxton,

University of Alabama, United States

Noel C. Barengo,

Florida International University,

United States

*Correspondence:

Elizabeth L. Budd

ebudd@uoregon.edu

Specialty section:

This article was submitted to Life-Course Epidemiology and Social Inequalities in Health,

a section of the journal

Frontiers in Public Health

Received: 19 July 2020 Accepted: 18 January 2021 Published: 15 February 2021

Citation:

Budd EL, Giuliani NR and Kelly NR (2021) Perceived Neighborhood Crime

Safety Moderates the Association Between Racial Discrimination Stress and Chronic Health Conditions Among Hispanic/Latino Adults.

Front. Public Health 9:585157.

doi: 10.3389/fpubh.2021.585157

\section{Perceived Neighborhood Crime Safety Moderates the Association Between Racial Discrimination Stress and Chronic Health Conditions Among Hispanic/Latino Adults}

\author{
Elizabeth L. Budd ${ }^{1,2 *}$, Nicole R. Giuliani ${ }^{2,3}$ and Nichole R. Kelly ${ }^{1,2}$ \\ ${ }^{1}$ Counseling Psychology and Human Services, College of Education, University of Oregon, Eugene, OR, United States, \\ ${ }^{2}$ Prevention Science Institute, University of Oregon, Eugene, OR, United States, ${ }^{3}$ Special Education and Clinical Sciences, \\ College of Education, University of Oregon, Eugene, OR, United States
}

Background: Little is known about the link between perceived neighborhood walkability and prevalence of chronic disease. Even less is known regarding this association among Hispanic/Latino adults, despite exhibiting high rates of chronic diseases. Stress due to racial discrimination is a harmful social determinant of health in Hispanics/Latinos. Having both low perceived neighborhood walkability and high racial discrimination stress may exacerbate the chronic disease status of Hispanics/Latinos. Among a U.S. national sample of Hispanic/Latino adults, this cross-sectional study aims to examine (1) the associations among overall perceived neighborhood walkability, racial discrimination stress, and having a chronic health condition; and (2) whether overall perceived neighborhood walkability moderates the hypothesized association between racial discrimination stress and having a chronic health condition.

Methods: In January 2018, 798 Hispanic/Latino adults ( $M$ age $=39.7$ years, SD $=15.1$; 58.6\% female; $70.0 \%$ U.S. born; 52.0\% Mexican/Mexican American) responded to a survey via Qualtrics Panels. Surveys included the Neighborhood Environment Walkability Scale-Abbreviated, Hispanic Stress Inventory-2, and self-reported presence/absence of chronic health conditions (e.g., hypertension, heart disease). A logistic regression was conducted testing for the moderation of the main effect of racial discrimination stress on the presence of a chronic health condition by overall perceived neighborhood walkability.

Results: After controlling for age, body mass index, and income, racial discrimination stress was inversely associated with overall perceived neighborhood walkability $(b=-0.18, p<0.001)$ and positively associated with having a chronic health condition $(\mathrm{OR}=1.02 ; 95 \% \mathrm{Cl}[1.00,1.03])$. While overall perceived neighborhood walkability was not associated with having a chronic health condition, perceived crime safety was inversely associated with having a chronic health condition $(O R=0.94 ; 95 \%$ $\mathrm{Cl}[0.89,0.99])$. Perceived crime safety moderated the positive association between discrimination stress and having a chronic health condition, such that the association was only significant among those who perceived their neighborhood to be less safe $(\beta=-0.004,95 \% \mathrm{Cl}[-0.01,-0.00])$. 
Conclusions: Overall perceived neighborhood walkability was inversely associated with racial discrimination stress, but not associated with having a chronic health condition. Perceived neighborhood crime safety, but not infrastructure or aesthetics, matters when it comes to the link between racial discrimination stress and having a chronic health condition among Hispanics/Latinos.

Keywords: Hispanic Americans, chronic disease, neighborhood, discrimination, stress

\section{INTRODUCTION}

In the United States, chronic diseases including cancer, coronary heart disease, and type 2 diabetes are the leading causes of death among Hispanics/Latinos $(1,2)$. Type 2 diabetes is also more prevalent among Hispanics/Latinos (17\%) compared with nonHispanic Whites (8\%) (3). Additionally, Hispanics/Latinos are more likely to develop type 2 diabetes at an earlier age and have more severe diabetes-related complications than the U.S. adult population overall (3).

Neighborhood walkability, which is how conducive the area around one's home is to walking, has been linked to prevalence of chronic disease (4-8). Most work on neighborhood walkability has employed objective measures such as land use, population density, crime rates, and/or proximity to parks (9). A 10-year longitudinal study employing objective measures found that, as neighborhoods became more walkable over time, community-wide diabetes prevalence and cardiovascular disease risk (e.g., high blood pressure and cholesterol) declined (8). Others have reported similar associations using objective measures of neighborhood walkability (4-6). The facilitation of physical activity is one behavioral mechanism identified as connecting greater objectively-measured walkability with lower prevalence of chronic disease (4, 9-12). In comparison, perceived neighborhood walkability is defined as the summation of a person's subjective evaluations of the environment around their home such as their perceptions of aesthetics, built environment features (e.g., presence of crosswalks), and/or safety from crime and traffic (9). A large, multi-country study found certain domains within perceived neighborhood walkability were associated with body mass index (BMI) (7). Most notably, greatest perceived safety from traffic and crime, and nearness to destinations (e.g., stores) were strongly associated with lower BMI (7). The association between perceived neighborhood walkability and chronic diseases is unknown. However, some evidence has suggested that one's perception of neighborhood walkability may have more influence on one's physical activity engagement than objective measures of neighborhood walkability $(13,14)$.

Furthermore, of the extant literature on the topic, Hispanic/Latino adults make up a small percentage of the overall participants investigated, despite having some of the highest rates of chronic diseases $(6,8,11)$. When Hispanics/Latinos are included in studies of neighborhood walkability, they are often compared to their non-Hispanic White peers, hindering our ability to capture within ethnic group variability in experiences, behaviors and health outcomes (15). These data are necessary to inform culturally tailored, community-based interventions to better address disparities in chronic diseases among Hispanic/Latino adults in the United States $(16,17)$.

A particularly salient social determinant of health among people of color in the United States is racial discrimination (18-20). The Psychosocial Stress Model explains that the stress associated with institutional racism and individual-level experiences with racism lead to health disparities, such as those documented among Hispanic/Latino adults (3, 18, 21). Institutional racial discrimination refers to systems or structural differences that manifest in inequitable distributions of resources and opportunities for people of color. Individuallevel experiences of racial discrimination are defined as one's experiences of being treated more poorly than others because of one's race or ethnicity. Empirical evidence suggests that heightened stress due to experiences of racial discrimination is linked to higher rates of chronic diseases by way of several pathways, such as heightened cortisol production, accelerated cellular aging, and poorer health behaviors, including physical activity avoidance, smoking, and greater alcohol consumption $(20,22-24)$. Meta-analysis results suggest that the inverse association between experiences of racial discrimination and general health may be particularly robust for Hispanic/Latino adults (25). Since experiences of discrimination often take place in public settings (26), including one's neighborhood, it is plausible that perceived neighborhood walkability and racial discrimination stress interact to increase risk for poor health behaviors and associated chronic disease risk. Additionally, neighborhood walkability can be described as an example of institutional racism, such that Hispanics/Latinos disproportionately live in low socioeconomic areas, which is associated with lower objective and perceived neighborhood walkability $(27,28)$. Theoretical models and empirical literature tend to suggest one's environment is a moderator in the association between psychosocial factors and health/health behaviors $(18,29,30)$. However, the association between perceived neighborhood walkability and racial discrimination stress and how they interact in their associations with chronic diseases among Hispanics/Latinos in the United States are unknown.

Among a national sample of U.S. Hispanic/Latino adults, this study aims to (1) test the associations among overall perceived neighborhood walkability, racial discrimination stress, and having a chronic health condition; and (2) examine whether overall perceived neighborhood walkability moderates the association between racial discrimination stress and having a chronic health condition. 
Informed by the aforementioned literature, hypotheses to the study aims are outlined as follows. Regarding aim 1, it is hypothesized that there will be a significant inverse association between racial discrimination stress and overall perceived neighborhood walkability $(26,28,31)$; a significant positive association between racial discrimination stress and having a chronic health condition (18, 20, 22-25); and a significant inverse association between overall perceived neighborhood walkability and having a chronic health condition (7, 11). Regarding aim 2, it is hypothesized that overall perceived neighborhood walkability will significantly moderate the association between racial discrimination stress and having a chronic health condition $(18,29,30)$, such that higher overall perceived neighborhood walkability will reduce the strength of the association between racial discrimination stress and having a chronic health condition, adjusting for age, BMI, annual household income, acculturation, U.S. region of residence, and health insurance status (32-41).

The findings of this study advance the literature by elucidating the associations among social and environmental factors and the presence of a chronic health condition among Hispanic/Latino adults, a sizable sub-set of the U.S. population at heightened risk for chronic diseases $(3,21)$. A better understanding of these associations could inform culturally tailored, communitybased strategies to better promote healthy behaviors and prevent chronic diseases among Hispanics/Latinos in the United States $(16,17,42)$.

\section{MATERIALS AND METHODS}

\section{Data Collection}

In January 2018, Qualtrics Panels was used to recruit Hispanic/Latino adults to complete a 197-question electronic survey in English or Spanish, which assessed their demographic information, health behaviors, physical and mental health conditions, and perceptions of their social and physical environments. Measures in the survey that were not already validated in Spanish were translated forward and backward to Spanish from English by two bi-lingual research assistants. Eligible respondents were 18 years or older, identified as Hispanic or Latino, resided in the United States, and were fluent in English or Spanish. Qualtrics Panels partners with over 20 online panel providers, namely market research panels, to supply a nationwide sample of potential participants who fit the eligibility requirements of this cross-sectional study (43).

Potential research participants were contacted by Qualtrics Panels via an email invitation. To avoid self-selection bias, the specific details of the study were not included in the email invitation. Those who expressed interest in participating were sent study details and underwent informed consent protocols in line with the committee responsible for human experimentation (institutional and national) and with the World Medical Association's Declaration of Helsinki. Specifically, prior to taking the survey, all participants provided their consent by selecting a radial button that read, "I have read the contents of this consent form. I give my consent to participate in this study," which appeared at the bottom of the electronic informed consent form.
Written documentation of consent was waived. Participants who completed the survey, received a pre-determined amount of points (stated in the email invitation to participate in the study). The amount of points was determined by the length of the survey, participant's specific panelist profile, and target acquisition difficulty. The points earned for completion of the survey can be redeemed for cash, airline miles, gift cards, points on online games, sweepstakes entrances and vouchers. This research protocol was approved by the Institutional Review Board at the University of Oregon. The dataset analyzed for this study can be found in the Harvard Dataverse, (44).

\section{Measures}

Demographic characteristics of the respondents were assessed using the Demographic and Health Information Data Questionnaire (45, 46). Demographic characteristics reported in this study include respondents' age, height, weight, gender, ethnic origin, whether English was their first language, nativity, acculturation, highest level of education, employment status, U.S. region of residence, relationship status, health insurance status, and annual household income. Response options for all demographic characteristics appear in Table 1. BMI was calculated using the following equation: $703 \times$ weight (lbs) $/[$ height (in) $] \wedge 2$ (47). Seven respondents were excluded from the analyses because of seemingly implausible BMI values $(<12$ or $>65)$. Annual household income was assessed by asking respondents to select the total combined income that is made yearly by all working members of their household from 11 U.S. dollar ranges. Response options were collapsed into: $<\$ 10,000-\$ 29,000, \$ 30,000-\$ 69,999$, and $\$ 70,000-\$ 100,000+$. Acculturation was assessed with The Abbreviated Multidimensional Acculturation Scale, which includes 6 U.S. cultural identity items (e.g., "I think of myself as being U.S. American"), nine English language competence items (e.g., "How well do you speak English on the phone?"), and six U.S. cultural competence items (e.g., "How well do you know popular American television shows?") (48). U.S. cultural identity items were assessed on a Four-point-Likert scale with response options ranging from 1 ("strongly disagree") to 4 ("strongly agree"). English language competence and U.S. cultural competence were assessed on a Four-point-Likert scale with response options ranging from 1 ("not at all") to 4 ("extremely well"). The Abbreviated Multidimensional Acculturation Scale has been shown to produce reliable and valid responses among Hispanics/Latinos (48). A mean was calculated to create a total U.S. acculturation score from all of the items within the U.S. cultural identity, English language competence, and U.S. cultural competence sub-scales. A higher mean score denotes a greater degree of acculturation to the United States.

The independent variable, racial discrimination stress, was measured by the total score of the Discrimination Stress subscale (11 items; e.g., "I was discriminated against because of my customs and cultural celebrations") from the Hispanic Stress Inventory-2. The Discrimination Stress sub-scale assesses psychosocial stress from discriminatory experiences related to being Hispanic. For each item, respondents were asked if they 
TABLE 1 | Descriptive characteristics of the study sample and key study variables.

\begin{tabular}{|c|c|c|c|c|c|c|}
\hline Variable & $N$ & Missing & $\begin{array}{l}\text { Mean } \\
\text { (S.D.) }^{a}\end{array}$ & $\begin{array}{c}\text { Skewness } \\
\text { (S.E.) }^{\text {b }}\end{array}$ & $\begin{array}{c}\text { Kurtosis } \\
\text { (S.E.) }\end{array}$ & $\begin{array}{l}\text { Min., } \\
\text { Max. }\end{array}$ \\
\hline \multirow[t]{2}{*}{ Age } & 797 & 1 & 39.65 & 0.307 & -0.955 & 18,81 \\
\hline & & & 15.05 & 0.087 & 0.173 & \\
\hline $\begin{array}{l}\text { Body mass } \\
\text { index }\end{array}$ & 774 & 24 & $\begin{array}{c}28.3 \\
7.266\end{array}$ & $\begin{array}{l}1.06 \\
0.088\end{array}$ & $\begin{array}{l}1.72 \\
0.176\end{array}$ & $\begin{array}{l}13.70 \\
64.19\end{array}$ \\
\hline \multirow[t]{2}{*}{ Acculturation } & 791 & 7 & 71.46 & -1.18 & 1.83 & 21,84 \\
\hline & & & 10.59 & 0.087 & 0.174 & \\
\hline $\begin{array}{l}\text { Perceived } \\
\text { neighborhood } \\
\text { walkability }\end{array}$ & 794 & 4 & $\begin{array}{c}46.88 \\
7.25\end{array}$ & $\begin{array}{r}-0.184 \\
0.087\end{array}$ & $\begin{array}{l}0.014 \\
0.173\end{array}$ & 21,64 \\
\hline $\begin{array}{l}\text { Racial } \\
\text { discrimination } \\
\text { stress }\end{array}$ & 789 & 9 & $\begin{array}{c}14.237 \\
12.67\end{array}$ & $\begin{array}{l}0.937 \\
0.087\end{array}$ & $\begin{array}{l}0.35 \\
0.174\end{array}$ & 0,55 \\
\hline
\end{tabular}

\begin{tabular}{|c|c|}
\hline Variable & $N$ (Valid \%) \\
\hline \multicolumn{2}{|l|}{ Gender } \\
\hline Woman & $467(58.6)$ \\
\hline Man & $320(40.2)$ \\
\hline Transgender & $8(1.0)$ \\
\hline Other & $2(0.3)$ \\
\hline Missing & 1 \\
\hline \multicolumn{2}{|l|}{ Ethnic origin } \\
\hline Mexican or Mexican American & $415(52.0)$ \\
\hline Puerto Rican & $136(17.0)$ \\
\hline Cuban & $68(8.5)$ \\
\hline Spanish & $44(5.5)$ \\
\hline Dominican & $27(3.4)$ \\
\hline Another Hispanic or Latino origin (e.g., Columbian, & $108(13.5)$ \\
\hline \multicolumn{2}{|l|}{ Venezuelan, Peruvian) } \\
\hline Missing & 0 \\
\hline \multicolumn{2}{|l|}{ English is first language } \\
\hline Yes & $522(65.4)$ \\
\hline No & $276(34.6)$ \\
\hline Missing & 0 \\
\hline \multicolumn{2}{|l|}{ Nativity } \\
\hline U.S. born & $556(70.0)$ \\
\hline Born outside of the United States & $238(30.0)$ \\
\hline Missing & 4 \\
\hline \multicolumn{2}{|l|}{ Highest level of education completed } \\
\hline Less than high school & $22(2.8)$ \\
\hline High school or GED & $217(27.6)$ \\
\hline Trade/Technical school & $60(7.6)$ \\
\hline 2-year college & $162(20.6)$ \\
\hline 4-year college/university & $237(30.2)$ \\
\hline Professional/Graduate & $88(11.2)$ \\
\hline Missing & 12 \\
\hline \multicolumn{2}{|l|}{ Employment status } \\
\hline Work full-time & $395(49.7)$ \\
\hline Work part-time & $114(14.3)$ \\
\hline Unemployed but looking for a job & $97(12.2)$ \\
\hline Do not work (e.g., stay-at home parent, retired, on disability, etc.) & $189(23.8)$ \\
\hline
\end{tabular}

(Continued)
TABLE 1 | Continued

\begin{tabular}{lc}
\hline Variable & $\boldsymbol{N}$ (Valid \%) \\
\hline Missing & 3 \\
Relationship status & \\
I am married or in a civil union & $364(45.6)$ \\
I am single, I do not have a spouse or partner & $284(35.6)$ \\
I am not married, but in a relationship & $132(16.5)$ \\
I am widowed & $18(2.3)$ \\
Missing & 0 \\
U.S. region of residence & \\
South & $316(39.6)$ \\
West & $182(22.8)$ \\
Northeast & $155(19.4)$ \\
Midwest & $145(18.2)$ \\
Missing & 0
\end{tabular}

\section{Health insurance status}

Private insurance (e.g., HMO, PPO)

$392(49.1)$

Public insurance (e.g., Medicare, Medicaid) 304 (38.1)

Uninsured

Missing

$102(12.8)$

0

Annual household income

$<\$ 10,000-29,000$

$231(29.0)$

$\$ 30,000-69,999+37.6)$

\$70,000-100,000+ 266 (33.4)

Missing

1

Current chronic health conditions reported

High cholesterol

$175(21.9)^{\mathrm{c}}$

Heart disease $\quad 27$ (3.4)

Cancer $15(1.9)$

Hypertension $181(22.7)$

Type 2 diabetes $122(15.3)$

None $\quad 54$ (6.8)

Missing 0

Presence of a chronic health condition

At least one current chronic health condition $362(45.4)$

No current chronic health conditions 436 (54.6)

Missing 0

a S.D.: standard deviation; ${ }^{b}$ S.E.: standard error; ${ }^{c}$ Respondents could report having more than one chronic health condition, thus, percentages reflect the proportion of the sample that endorsed having each of the listed chronic health conditions.

have experienced the reported stressor (Yes/No), and if they had experienced the stressor, they were asked to rate how stressful the event was on a five-point-Likert scale ranging from 1 ("not at all worried/tense") to 5 ("extremely worried/tense"). Possible scores ranged from zero to 55 and higher scores indicate greater racial discrimination stress. The Hispanic Stress Inventory2 sub-scales have been shown to produce reliable and valid responses in Spanish and English among a diverse sample of Hispanic/Latino adults in the United States $(49,50)$. In this sample, the Discrimination Stress sub-scale had good reliability $(\alpha=.933)$. 
The dependent variable, presence of a chronic health condition, was assessed by one question from the Demographic and Health Information Data Questionnaire (45, 46). Respondents were asked to indicate all of the health conditions they currently have from the following: high cholesterol, overweight/obesity, heart disease, cancer (specify the type), high blood pressure, type 2 diabetes, other (specify), or to select "I do not have any of these health conditions."

The hypothesized moderator, overall perceived neighborhood walkability, was measured using a total sum score of four subscale scores from the Neighborhood Environment Walkability Scale- Abbreviated (NEWS-A) including: infrastructure for walking/cycling (six items; e.g., "There are sidewalks on most of the streets in my neighborhood"), aesthetics (four items; e.g., "There are trees along the streets in my neighborhood"), traffic safety (three items; e.g., "The speed of traffic on most nearby streets is usually slow (30 mph or less)"), and crime safety (three items; e.g., "The crime rate in my neighborhood makes it unsafe to go on walks during the day") (51). Respondents chose from four-point Likert scale response options ranging from 1 ("strongly disagree") to 4 ("strongly agree") for each item. Five items were reverse coded to align with the direction of the other items. Possible scores ranged from 16 to 64 and higher scores indicate greater overall perceived neighborhood walkability. The scale has demonstrated validity and reliability in English and Spanish $(52,53)$. In this sample, the overall NEWS-A had adequate reliability $(\alpha=0.761)$.

\section{Analyses}

Descriptive statistics were conducted to review missing cases and response distributions for scale variables with a skew or kurtosis outside of \pm 2 (54). Preliminary analyses also included a Pearson correlation in order to examine potential multicollinearity $(r>$ \pm 0.80 ) between key study variables and independent-samples $t$-tests to assess unadjusted associations between key study variables and the dependent variable (55).

Regarding the dependent variable, having "overweight/obesity" was removed as one of the chronic conditions. Instead, BMI was included as a covariate in the regression models because of its association with chronic disease risk (39). Respondents endorsed having up to four of the six included chronic health conditions. Of those who endorsed having at least one of the health conditions, $60.22 \%$ reported having only one of the conditions followed by $23.48 \%$ with two. Given this distribution, responses were dichotomized into whether the respondent endorsed currently having either any or none of the health conditions. Prior research also supports treating presence of a chronic health condition as a binary term $(36,56)$, given meaningful differences between the two groups in health service use (e.g., emergency room visits) and general medical expenditures (36).

To address study aim 1, one multiple linear regression model and two binary logistic regression models were conducted. Age, annual household income, BMI, acculturation, U.S. region of residence, and health insurance status were initially included in these models as covariates because of their associations with having a chronic health condition (32-41). In pursuit of parsimonious models, covariates were removed that had non-significant ( $p \geq 0.05$ ) regression coefficients in all of the regression models conducted for study aims 1 and 2, and also had no notable effects on the models' variance explained or results when they were removed (57). First, the association between overall perceived neighborhood walkability and racial discrimination stress, adjusting for the covariates, was assessed in a multiple linear regression model. Second, the main effects of racial discrimination stress on presence of a chronic health condition, adjusting for the covariates, was investigated using binary logistic regression. Third, the main effects of overall perceived neighborhood walkability on the presence of a chronic health condition, adjusting for the covariates, was conducted using binary logistic regression. The binomial assumption was assumed because there was no reason to believe there was dependence among observations or that the sample was nonrandom (58).

For study aim 2, overall perceived neighborhood walkability and racial discrimination stress were grand-mean centered and an interaction term was created. A binary logistic model was conducted that included: the covariates, centered overall perceived neighborhood walkability, centered racial discrimination stress, and the interaction term. All statistical analyses were conducted in IBM SPSS Statistics for Windows, Version 26 (59). The moderation plot was conducted in $\mathrm{R}$, Version 3.6.1 using the interactions package $(60,61)$.

\section{Exploratory Analyses}

For post hoc exploratory purposes, aims 1 and 2 were reexamined using the individual sub-scales of the NEWSA. Infrastructure for walking/cycling $(\alpha=0.764)$, aesthetics ( $\alpha=0.799$ ), and crime safety $(\alpha=0.912)$ demonstrated adequate to good reliability in this sample. Traffic safety demonstrated poor reliability $(\alpha=0.258)$ in this sample and was thus not included in the exploratory analyses. Preliminarily, Pearson correlations were conducted to assess associations among the three sub-scales. The same statistical procedures were conducted as described earlier for the study aims, except they were repeated three times, once for each NEWS-A sub-scale.

\section{RESULTS}

\section{Sample}

The survey respondents included 798 Hispanic/Latino adults 18-81 years old $(M=39.7 \pm 15.1$ years; BMI $M=28.30$ $\pm 7.3 \mathrm{~kg} / \mathrm{m}^{2}$; Table 1). Approximately $20 \%$ of respondents completed the survey in Spanish, 80\% in English. The majority of the sample identified as women (58.6\%); Mexican or Mexican American (52\%); native English speakers (65.4\%); U.S. born (70.0\%); educated through 2 years of college or beyond $(62 \%)$; and employed at least part time (64\%). Respondents resided in all major regions of the United States, with the largest portion living in the South (39.6\%). Additionally, the largest proportions of respondents had a least one chronic health condition (45.4\%); were married or in a civil union $(45.6 \%)$; had public or private health insurance $(87.2 \%)$; and an annual household income of $\$ 30,000-69,999$ (37.6\%). 


\section{Preliminary Findings}

In unadjusted associations, there was a significant inverse association between overall perceived neighborhood walkability and racial discrimination stress $(r=-0.166, p<0.01)$. The mean scores of overall perceived neighborhood walkability $\left(t_{(787)}=-0.695, p=0.487\right)$ and racial discrimination stress $\left(t_{(792)}=-0.963, p=0.336\right)$ were not significantly different for those with or without a chronic health condition.

\section{Study Aim 1 Results}

The covariates retained in aim 1 and aim 2 regression models were age, BMI, and annual household income. There was a significant and inverse association between overall perceived neighborhood walkability and racial discrimination stress $\left(b=-0.18, p<0.001 ; R^{2}=0.07\right)$.

Table 2 provides an overview of results from the logistic regression analyses. In Model 1, there was a significant and positive association between racial discrimination stress and the presence of a chronic health condition (Odds Ratio $[\mathrm{OR}]=1.017 ; 95 \%$ Confidence Interval [CI] [1.004, 1.030]). In Model 2, there was no significant association between overall perceived neighborhood walkability and the presence of a chronic health condition (OR $=0.993 ; 95 \% \mathrm{CI}$ $[0.72,1.015])$.

\section{Study Aim 2 Results}

The full model results displayed in Model 3 within Table 2 show that the interaction between racial discrimination stress and perceived walkability on having a chronic health condition was not significant $(\mathrm{OR}=0.999 ; 95 \% \mathrm{CI}[0.997,1.001])$, suggesting the association between racial discrimination stress and health did not vary by overall perceived neighborhood walkability. Model 3 explained a total $17.8 \%$ of the variance in the presence of a chronic health condition.

\section{Exploratory Results}

Unadjusted bivariate associations among the three NEWS-A sub-scales showed crime safety was inversely associated with infrastructure for walking/cycling $(r=-0.106, p<0.01)$ and not significantly associated with aesthetics $(r=0.059, p=0.09)$. Infrastructure for walking/cycling was positively associated with aesthetics $(r=0.520, p<0.01)$.

Table 3 shows the association between each NEWS-A subscale and racial discrimination stress, adjusted for age, BMI, and annual household income. Only crime safety was significantly and inversely associated with racial discrimination stress $(b=-0.27, p<0.001)$.

Among the three NEWS-A sub-scales, there was only a significant and inverse association between crime safety and the presence of a chronic health condition $(\mathrm{OR}=0.936$; 95\% CI [0.887, 0.988]; Table 4). There was also a significant moderating effect of crime safety on the association between racial discrimination stress and presence of a chronic health condition. Specifically, there was a significant and positive association between discrimination stress and having a chronic health condition, only among those who perceived their neighborhood to be less safe $(\beta=-0.0043, \mathrm{SE}=0.0021$, CI $[-0.0084,-0.0002], p<0.05$; Figure 1).

TABLE 2 | Logistic regression results for predicting presence of a chronic health condition among U.S. Hispanic/Latino adults.

\begin{tabular}{|c|c|c|c|c|c|c|}
\hline Variables & \multicolumn{2}{|c|}{ Model 1} & \multicolumn{2}{|c|}{ Model 2} & \multicolumn{2}{|c|}{ Model 3} \\
\hline Age & $1.047^{\star \star \star}$ & $1.036-1.059$ & $1.044^{\star \star \star}$ & $1.033-1.056$ & $1.047^{\star \star \star}$ & $1.035-1.059$ \\
\hline \multicolumn{7}{|l|}{ Annual household income } \\
\hline$<\$ 10,000-\$ 29,000$ & ref & & ref & & ref & \\
\hline$\$ 70,000-\$ 100,000+$ & $1.697^{\star \star}$ & $1.139-2.527$ & $1.763^{\star *}$ & $1.185-2.622$ & $1.721^{\star \star}$ & $1.152-2.572$ \\
\hline Body mass index & $1.046^{\star \star \star}$ & $1.023-1.069$ & $1.047^{\star \star \star}$ & $1.024-1.070$ & $1.046^{\star \star \star}$ & $1.023-1.069$ \\
\hline Racial discrimination stress & $1.017^{*}$ & $1.004-1.030$ & $\mathrm{~N} / \mathrm{A}$ & & $1.016^{\star}$ & $1.003-1.029$ \\
\hline Perceived neighborhood walkability & $N / A^{c}$ & & 0.993 & $0.972-1.015$ & 0.996 & $0.974-1.018$ \\
\hline $\begin{array}{l}\text { Perceived neighborhood walkability } X \\
\text { Racial discrimination stress }\end{array}$ & $\mathrm{N} / \mathrm{A}$ & & $\mathrm{N} / \mathrm{A}$ & & 0.999 & $0.997-1.001$ \\
\hline Degrees of freedom & 5 & & 5 & & 7 & \\
\hline Hosmer and Lemeshow chi-square & $15.937^{\star}$ & & 11.579 & & 12.259 & \\
\hline Degrees of freedom & 8 & & 8 & & 8 & \\
\hline Nagelkerke R-squared & 0.177 & & 0.169 & & 0.178 & \\
\hline
\end{tabular}

${ }^{a}$ Odds ratios for the constant not displayed in the table; ${ }^{b}$ ref, reference group; ${ }^{c} N / A$, variable is not applicable to the model; ${ }^{d}$ Model 3 includes grand-mean centered variables: perceived neighborhood walkability, racial discrimination stress, and the interaction term; ${ }^{*} p<0.05,{ }^{\star *} p<0.010,{ }^{* \star \star} p<0.001$ (two-tailed). 
TABLE 3 | Adjusted associations between each Neighborhood Environment Walkability Scale- abbreviated sub-scale and racial discrimination stress among U.S. Hispanic/Latino adults.

\begin{tabular}{|c|c|c|c|c|c|c|c|}
\hline Variable & $b$ & 95\% Confidence interval & S.E. ${ }^{a}$ & $t$ & $d f^{b}$ & $p$ & $R^{2}$ \\
\hline Infrastructure for walking/cycling & -0.030 & $-0.211-0.086$ & 0.076 & -0.827 & 793 & 0.408 & 0.033 \\
\hline Aesthetics & -0.036 & $-0.314-0.103$ & 0.106 & -0.991 & 793 & 0.322 & 0.033 \\
\hline Crime safety & -0.265 & $-0.959-0.595$ & 0.102 & -7.472 & 793 & $<0.001$ & 0.099 \\
\hline
\end{tabular}

a S.E.: standard error; ${ }^{b} d f:$ degrees of freedom; ${ }^{c}$ Covariates in the multiple linear regression models include age, body mass index, and annual household income.

\section{DISCUSSION}

The present study examined (1) the associations among overall perceived neighborhood walkability, racial discrimination stress, and having a chronic health condition; and (2) whether overall perceived neighborhood walkability moderated the hypothesized association between racial discrimination stress and having a chronic health condition among a U.S. national sample of Hispanic/Latino adults. Study findings advance the understanding of how experiences such as, how individuals perceive the safety of their neighborhoods and the degree to which individuals experience racial discrimination stress, vary among Hispanics/Latinos in the United States and how these experiences are associated with having a chronic health condition. The study findings can inform next steps in research and practice that aim to eliminate current chronic disease disparities among Hispanic/Latino adults and details for which are provided below $(3,21)$.

As hypothesized, those who reported experiencing more racial discrimination stress had higher odds of having a chronic health condition after adjusting for age, BMI, and annual household income. This finding is consistent with The Psychological Stress Model (18) and extant literature among Hispanics/Latinos and other racial/ethnic miniories $(19,23,25,49)$. While the increased odds for having a chronic health condition among those who report more racial discrimination stress was marginal in this study, alongside the extant literature, the finding reinforces the importance of reducing racial discrimination against Hispanics/Latinos in the United States in order to promote health equity.

Furthermore, as hypothesized $(26,28,31)$, an inverse association, although weak, was found between overall perceived neighborhood walkability and racial discrimination stress. Overall perceived neighborhood walkability is a total of four individual sub-scales. Exploratory results indicated perceived safety from crime, not perceived infrastructure for walking/cycling and aesthetics of one's neighborhood, was the driver of the inverse association found between overall perceived neighborhood walkability and racial discrimination stress. These findings not only advance our understanding of the association between these environmental and social factors among U.S. Hispanic/Latino adults, they are also novel to the broader literature not focused on Hispanics/Latinos. In related literature, a systematic review found consistent support for the inverse association between objectively measured neighborhood walkability and general psychosocial distress (62). In addition to focusing on objective vs. perceived neighborhood walkability, the reviewed studies did not assess racial discrimination stress specifically and only one of the studies, by Brown and colleagues (63), was strictly among U.S. Hispanic/Latino adults $(62,63)$. Brown et al.'s (63) study involved low socioeconomic, U.S. Hispanic/Latino, older adults and found that front porches were positively associated with social support, which was associated with lower psychological distress (63). The presence of front porches is most similar to items in the infrastructure for walking/cycling sub-scale within the NEWS-A. This association between infrastructure for walking/cycling and racial discrimination stress was not identified in the present study, which could be due to the use of different measures of perceived neighborhood walkability between the studies and substantial demographic differences between the study samples. Future research could investigate social support and other potential links connecting perceived neighborhood crime safety and racial discrimination stress among Hispanic/Latino adults.

Contrary to the hypothesis, overall perceived neighborhood walkability was not associated with having a chronic health condition. However, exploratory findings showed that perceived neighborhood safety from crime was inversely associated with having a chronic health condition. Both of these findings contribute toward filling the gap in knowledge regarding perceived (vs. objective) neighborhood walkability and chronic diseases $(4-6,8)$. There is a precedent for perceived neighborhood safety playing a pivotal role in behavioral and health risk factors for chronic diseases in the literature. For example, another study of Hispanics/Latinos found infrastructure for walking/cycling was positively associated with physical activity, but only when perceived crime was low (64). Also, a multi-country study by De Bourdeaudhuij and colleagues (7) found perceived neighborhood safety from traffic and crime, and nearness to destinations were inversely associated with BMI, adjusting for relevant demographic factors (7). Where BMI was the dependent variable in De Bourdeaudhuij's (7) study, BMI was a covariate in the present study. The latter approach is advantageous when aiming to reduce chronic disease rates among Hispanics/Latinos, as higher BMI is just one of many risk factors for chronic diseases (65).

Overall perceived neighborhood walkability did not moderate the association between racial discrimination stress and presence of a chronic health condition, contrary to the hypothesis. However, exploratory findings did identify a significant moderating effect of perceived crime safety on the association between racial discrimination stress and 
TABLE 4 | Predicting presence of a chronic health condition and testing for moderating effects of perceived neighborhood walkability sub-scales among U.S. Hispanic/Latino adults.

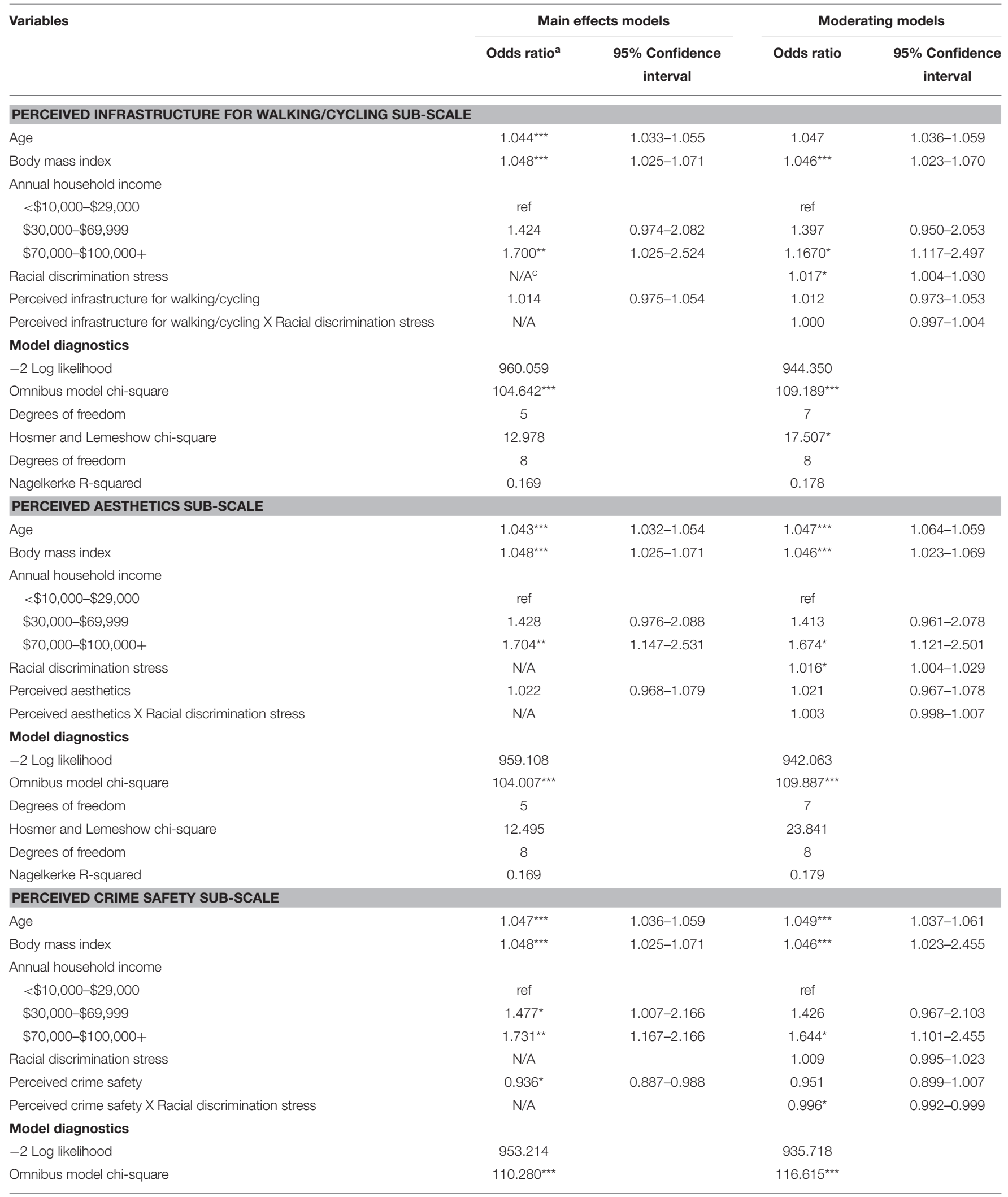


TABLE 4 | Continued

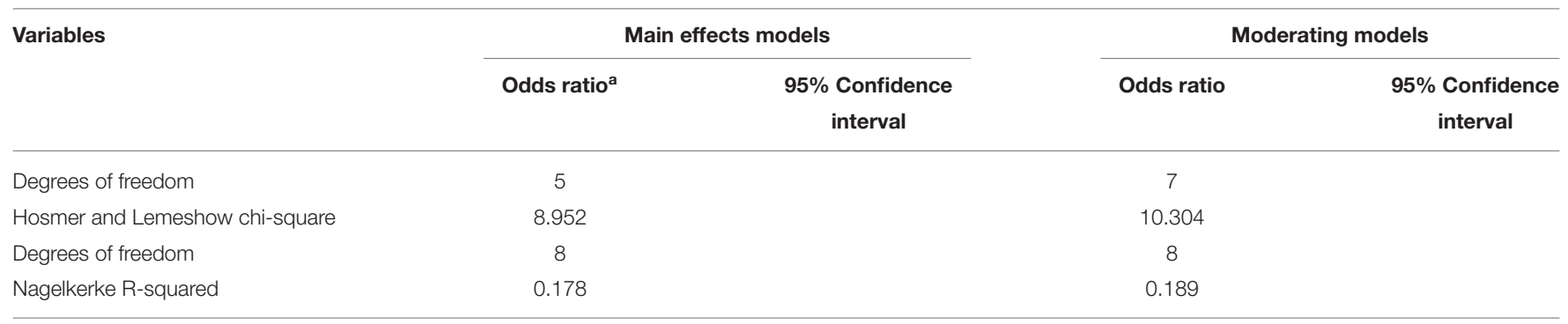

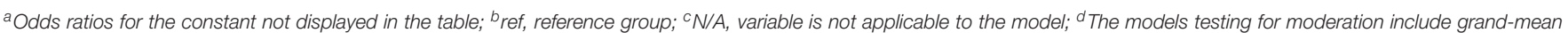
centered variables for perceived neighborhood walkability sub-scales, perceived racial discrimination stress, and the interaction terms; ${ }^{*} p<0.05$, ${ }^{* *} p<0.010$, ${ }^{* * *} p<0.001$ (two-tailed).

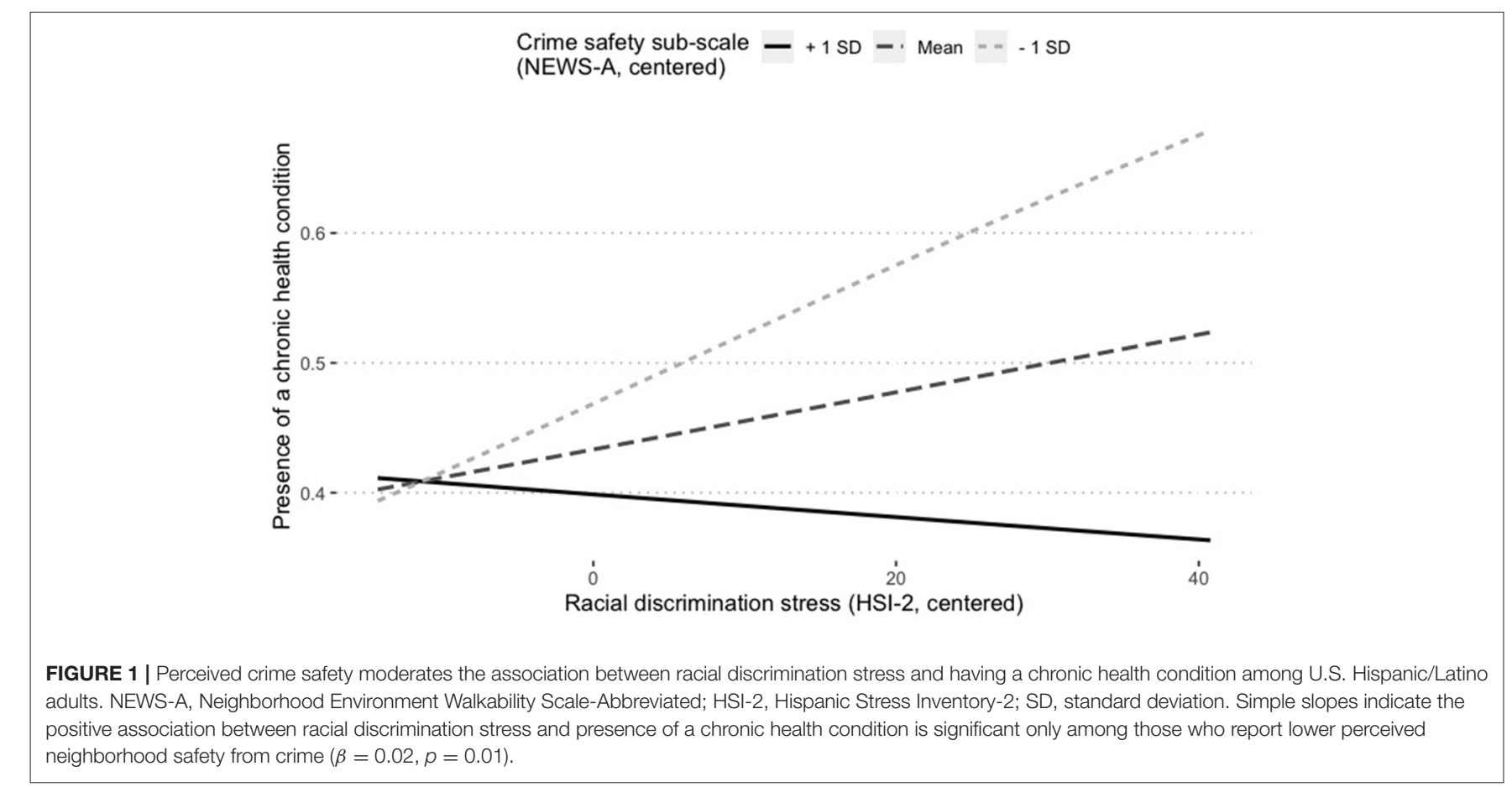

presence of a chronic health condition. Specifically, the positive association between racial discrimination stress and presence of a chronic health condition is significant only among those who report lower perceived neighborhood safety from crime. This finding is consistent with theoretical models and empirical literature that have characterized the environment as a moderator of the association between psychosocial factors and health/health behaviors $(18,29,30)$. The findings also highlight the importance of studying and targeting the perceived walkability of neighborhoods in more specific rather than general ways. Examining the study aims by each NEWS-A sub-scale brought clarity where overall perceived neighborhood walkability could not.

This study's findings suggest perceived neighborhood safety matters, not infrastructure and aesthetics, when it comes to racial discrimination stress and having a chronic health condition among Hispanics/Latinos. Low perceived neighborhood safety from crime could reflect institutional racism, as Hispanics/Latinos are more likely than non-Hispanic
Whites to be victims of violent crimes and more likely to live in poverty, which is associated with higher crime rates $(66,67)$. Improving safety in communities where Hispanic/Latino residents report greater safety concerns may have beneficial effects on racial discrimination stress and health among Hispanic/Latino adults. Testing such an intervention in a longitudinal study is a recommended next step in research.

This study responds to calls in the literature to investigate innovative explanations for health disparities by testing interactions of the physical and social environments $(68,69)$. A study that examined the moderating role of the environment on racial discrimination stress and health among African Americans found that discrimination experienced in the previous year was positively associated with cortisol concentration among those residing in neighborhoods with more White residents (69). Building on the present study's findings by including an additional aspect of the social environment, such as social capital (70), perceived neighborhood social cohesion (71), or neighborhood racial makeup (69), may explain more of the 
total variance in presence of a chronic health condition among Hispanic/Latino adults.

The study sample reflected the Hispanic/Latino population in the United States well on a number of sociodemographic characteristics including proportions by ethnic origins, nativity, employment status, relationship status, and health insurance status $(72,73)$. The sample appears to over represent women (sample 58\% vs. U.S. $49 \%$ ) and those who have completed 2 years or more of college (sample $62 \%$ vs. U.S. $41 \%$ ), and underrepresent those living in the Western region of the United States (sample $23 \%$ vs. $41 \%)(73,74)$. These disproportionate representations in the sample could have implications for the findings, but explanations follow that propose the implications may be minimal. Suspecting the study results could vary by gender, post hoc analyses were conducted and the study findings did not change when examined by women and men. Additionally, those with more education are more likely to have a primary healthcare provider and more likely to effectively manage chronic health conditions, like hypertension, than those less educated $(75,76)$. Thus, this study's findings could reflect the experiences of a healthier group of Hispanics/Latinos than the average national cross-section of Hispanics/Latinos. A RAND Corporation report on nationally representative data from the Medical Expenditure Panel Survey from 2014 shows that $49 \%$ of Hispanic/Latino adults in the United States have at least one chronic health condition. This is $3.6 \%$ more than respondents endorsed in this study, and the two studies generally assessed the same conditions. Finally, the Western region of the United States, California in particular, is home to the largest proportion of the U.S. Hispanic/Latino population. One national survey found that the West generally fares better on indices of residential, racial integration than other U.S. regions, but the state of race relations between non-Hispanic Whites and Hispanic/Latinos were similar to the rest of the country (77). Region was also included in the initial analyses as a covariate and removed only after it was determined to not be an explanatory contributor to the models.

\section{Strengths and Limitations}

The most notable strengths of this study are the several novel findings that advance the literature and inform next steps in practice and research that aim to address health disparities among Hispanic/Latino adults in the United States. Additional study strengths are that the survey was provided in English and Spanish and the sample reflected the U.S. Hispanic/Latino population well on a number of characteristics; both increase generalizability of the study results. A large sample size of Hispanic/Latino adults provides ample power to test for moderation, which is often underpowered in the literature (78), and allows for the examination of within ethnic group variability in experiences and chronic health conditions.

Lastly, there are also study limitations. The cross-sectional design limits the study interpretations to associations rather than causal inferences. The inability to measure survey response rate using Qualtrics Panels and the un-measured differences between those who are more and less likely to participate in electronically delivered surveys makes the study vulnerable to selection bias.
Although, a meta-analysis by Walter and colleagues (79) did find similar internal reliability and external validity between online panel and other sampling techniques (79). The self-report measure of current chronic health conditions, as opposed to medically confirmed, likely underestimates the actual proportion of those who have chronic health conditions, as undiagnosed type 2 diabetes is common, especially among people of color in the United States (80). Future longitudinal studies should focus on disentangling mechanisms by chronic condition, as some mechanisms are shared and others are not. Finally, the racial discrimination stress measure was not specific to racial discrimination experienced in one's neighborhood, however, it does capture stress due to racial discrimination in the contexts of one's daily life, which would include the neighborhood in which one lives.

\section{CONCLUSION}

Novel insights of this study include the associations among perceived neighborhood walkability, racial discrimination stress, and having a chronic health condition among U.S. Hispanic/Latino adults, as well as evidence that perceived neighborhood safety plays a moderating role in the positive association between racial discrimination stress and having a chronic health condition. Improving safety in communities where Hispanic/Latino residents report greater safety concerns may have beneficial effects on racial discrimination stress and health among Hispanic/Latino adults.

\section{DATA AVAILABILITY STATEMENT}

The dataset analyzed for this study can be found in the Harvard Dataverse, https://doi.org/10.7910/DVN/NABLZX.

\section{ETHICS STATEMENT}

The study involving human participants was reviewed and approved by Institutional Review Board at the University of Oregon. Written informed consent for participation was not required for this study in accordance with the national legislation and the institutional requirements.

\section{AUTHOR CONTRIBUTIONS}

EB contributed to the conception and design of the study, analysis and interpretation of data, and drafting of the full manuscript. NG and NK contributed to the conception and design of the study, analysis and interpretation of data, and manuscript revisions. All authors read and approved the submitted version.

\section{ACKNOWLEDGMENTS}

The authors acknowledge the contributions of Jonathan A. Pedroza to the substantive content and Dr. Tasia M. Smith to the collection of these data and the conception of the study. Dr. Smith is deeply missed by the authors and her students. 


\section{REFERENCES}

1. Centers for Disease Control and Prevention. Leading Causes of Death Males - Hispanic - United States, 2016. Health Equity. (2016). Available online at: https://www.cdc.gov/healthequity/lcod/men/2016/hispanic/index. htm\#anchor_1571145367 (accessed October 13, 2020).

2. Balfour PC, Ruiz JM, Talavera GA, Allison MA, Rodriguez CJ. Cardiovascular disease in Hispanics/Latinos in the United States. J Lat Psychol. (2016) 4:98113. doi: $10.1037 /$ lat 0000056

3. Centers for Disease Control and Prevention. Hispanic/Latino Americans and Type 2 Diabetes. (2019). Available online at: https://www.cdc.gov/diabetes/ library/features/hispanic-diabetes.html (accessed May 22, 2020).

4. Creatore MI, Glazier RH, Moineddin R, Fazli GH, Johns A, Gozdyra P, et al. Association of neighborhood walkability with change in overweight, obesity, and diabetes. JAMA. (2016) 315:2211-20. doi: 10.1001/jama.2016.5898

5. Frank LD, Saelens BE, Powell KE, Chapman JE. Stepping towards causation: do built environments or neighborhood and travel preferences explain physical activity, driving, and obesity? Soc Sci Med. (2007) 65:1898914. doi: 10.1016/j.socscimed.2007.05.053

6. Renalds A, Smith TH. A systematic review of built environment and health. Fam Community Heal. (2010) 33:68-78. doi: 10.1097/FCH.0b013e3181c4e2e5

7. De Bourdeaudhuij I, Van Dyck D, Salvo D, Davey R, Reis RS, Schofield G, et al. International study of perceived neighbourhood environmental attributes and Body Mass Index: IPEN Adult study in 12 countries. Int J Behav Nutr Phys Act. (2015) 12:1-10. doi: 10.1186/s12966-015-0228-y

8. Howell NA, Tu JV, Moineddin R, Chu A, Booth GL. Association between neighborhood walkability and predicted 10 -year cardiovascular disease risk: The CANHEART (Cardiovascular Health in Ambulatory Care Research Team) Cohort. J Am Heart Assoc. (2019) 8:21. doi: 10.1161/JAHA.119.013146

9. Saelens BE, Handy SL. Built environment correlates of walking: a review. Med Sci Sport Exer. (2008) 40:S550-66. doi: 10.1249/MSS.0b013e31817c67a4

10. Wasfi RA, Dasgupta K, Orpana H, Ross NA. Neighborhood walkability and body mass index trajectories: Longitudinal study of Canadians. Am J Public Health. (2016) 106:934-40. doi: 10.2105/AJPH.2016.303096

11. Sallis JF, Floyd MF, Rodríguez DA, Saelens BE. Role of built environments in physical activity, obesity, and cardiovascular disease. Circulation. (2012) 125:729-37. doi: 10.1161/CIRCULATIONAHA.110.969022

12. Chandrabose M, Cerin E, Mavoa S, Dunstan D, Carver A, Turrell G, et al. Neighborhood walkability and 12-year changes in cardio-metabolic risk: the mediating role of physical activity. Int J Behav Nutr Phys Act. (2019) 16:1-11. doi: 10.1186/s12966-019-0849-7

13. Gebel K, Bauman AE, Sugiyama T, Owen N. Mismatch between perceived and objectively assessed neighborhood walkability attributes: prospective relationships with walking and weight gain. Heal Place. (2011) 17:51924. doi: 10.1016/j.healthplace.2010.12.008

14. Gebel K, Bauman A, Owen N. Correlates of non-concordance between perceived and objective measures of walkability. Ann Behav Med. (2009) 37:228-38. doi: 10.1007/s12160-009-9098-3

15. Furman R, Negi NJ, Iwamoto DK, Rowan D, Shukraft A, Gragg J. Social work practice with latinos. Soc Work. (2009) 54:167-74. doi: 10.1093/sw/54.2.167

16. Chin MH, Clarke AR, Nocon RS, Casey AA, Goddu AP, Keesecker NM, et al. A roadmap and best practices for organizations to reduce racial and ethnic disparities in health care. J Gen Intern Med. (2012) 27:9921000. doi: $10.1007 / \mathrm{s} 11606-012-2082-9$

17. Pasick RJ, D’onofrio CN, Otero-Sabogal R. Similarities and differences across cultures: questions to inform a third generation for health promotion research. Heal Educ Behav. (1996) 23:142-61. doi: 10.1177/109019819602301S11

18. Dressler WW, Oths KS, Gravlee CC. Race and ethnicity in public health research: models to explain health disparities. Annu Rev Anthropol. (2005) 34:231-52. doi: 10.1146/annurev.anthro.34.081804.120505

19. Williams DR, Neighbors HW, Jackson JS. Racial/ethnic discrimination and health. Am J Public Health. (2003) 93:200-8. doi: 10.2105/AJPH.93.2.200

20. De Vogli R, Brunner E, Marmot MG. Unfairness and the social gradient of metabolic syndrome in the Whitehall II Study. J Psychosom Res. (2007) 63:413-9. doi: 10.1016/j.jpsychores.2007.04.006

21. U.S. Department of Health and Human Services Office of Minority Health. Obesity and Hispanic Americans. (2018). Available online at: https:// minorityhealth.hhs.gov/omh/browse.aspx?lvl=4\&lvlid=70 (accessed May 22, 2020).
22. Epel ES, Lin J, Wilhelm FH, Wolkowitz OM, Cawthon R, Adler NE, et al. Cell aging in relation to stress arousal and cardiovascular disease risk factors. Psychoneuroendocrinology. (2006) 31:277-87. doi: 10.1016/j.psyneuen.2005.08.011

23. Williams DR, Mohammed SA. Discrimination and racial disparities in health: evidence and needed research. J Behav Med. (2009) 32:20. doi: 10.1007/s10865-008-9185-0

24. Busse D, Yim IS, Campos B. Social context matters: ethnicity, discrimination and stress reactivity. Psychoneuroendocrinology. (2017) 83:187-93. doi: 10.1016/j.psyneuen.2017.05.025

25. Paradies Y, Ben J, Denson N, Elias A, Priest N, Pieterse A, et al. Racism as a determinant of health: a systematic review and meta-analysis. PLOS ONE. (2015) 10:1-48. doi: 10.1371/journal.pone.0138511

26. Shelton RC, Puleo E, Bennett GG, McNeill LH, Goldman RE, Emmons KM. Racial discrimination and physical activity among low income- housing residents. Am J Prev Med. (2009) 37:541. doi: 10.1016/j.amepre.2009. 07.018

27. Sallis JF, Slymen DJ, Conway TL, Frank LD, Saelens BE, Cain K, et al. Income disparities in perceived neighborhood built and social environment attributes. Heal Place. (2011) 17:1274-83. doi: 10.1016/j.healthplace.2011. 02.006

28. Steinmetz-Wood M, Kestens Y. Does the effect of walkable built environments vary by neighborhood socioeconomic status? Prev Med (Baltim). (2015) 81:262-7. doi: 10.1016/j.ypmed.2015.09.008

29. Colabianchi N, Clennin MN, Dowda M, McIver KL, Dishman RK, Porter DE, et al. Moderating effect of the neighbourhood physical activity environment on the relation between psychosocial factors and physical activity in children: a longitudinal study. J Epidemiol Community Health. (2019) 73:598604. doi: 10.1136/jech-2018-211456

30. Gee GC, Payne-Sturges DC. Environmental health disparities: a framework integrating psychosocial and environmental concepts. Environ Health Perspect. (2004) 112:1645-53. doi: 10.1289/ehp.7074

31. Ding D, Sallis JF, Kerr J, Lee S, Rosenberg DE. Neighborhood environment and physical activity among youth a review. Am J Prev Med. (2011) 41:44255. doi: 10.1016/j.amepre.2011.06.036

32. Lovasi GS, Hutson MA, Guerra M, Neckerman KM. Built environments and obesity in disadvantaged populations. Epidemiol Rev. (2009) 31:720. doi: 10.1093/epirev/mxp005

33. Shaw K, Theis K, Self-Brown S, Roblin D, Barker L. Chronic disease disparities by county economic status and metropolitan classification, behavioral risk factor surveillance system, 2013. Prev Chronic Dis. (2016) 13:160088. doi: 10.5888/pcd13.160088

34. Prasad S, Sung B, Bharat AB. Age-associated chronic diseases require ageold medicine: role of chronic inflammation. Prev Med. (2012) 54:S2937. doi: 10.1016/j.ypmed.2011.11.011

35. Bland JS. Age as a modifiable risk factor for chronic disease. Integr Med. (2018) 17:16-9.

36. Buttorff C, Ruder T, Bauman M. Multiple Chronic Conditions in the United States. Santa Monica, CA: RAND Corporation (2017). doi: 10.7249/TL221

37. Sommers BD, Gunja MZ, Finegold K, Musco T. Changes in self-reported insurance coverage, access to care, and health under the Affordable Care Act. JAMA. (2015) 314:366-74. doi: 10.1001/jama.2015.8421

38. Wilper AP, Woolhandler S, Lasser KE, McCormick D, Bor DH, Himmelstein DU. Health insurance and mortality in US adults. Am J Public Health. (2009) 99:2289-95. doi: 10.2105/AJPH.2008.157685

39. Font-Burgada J, Sun B, Karin M. Obesity and cancer: the oil that feeds the flame. Cell Metab. (2016) 23:48-62. doi: 10.1016/j.cmet.2015.12.015

40. Oates GR, Jackson BE, Partridge EE, Singh KP, Fouad MN, Bae S. Sociodemographic patterns of chronic disease: how the mid-South region compares to the rest of the country. Am J Prev Med. (2017) 52:S319. doi: 10.1016/j.amepre.2016.09.004

41. Argeseanu Cunningham S, Ruben JD, Venkat Narayan KM. Health of foreign-born people in the United States: a review. Heal Place. (2008) 14:623-35. doi: 10.1016/j.healthplace.2007. 12.002

42. Barrera M, Castro FG, Strycker LA, Toobert DJ. Cultural adaptations of behavioral health interventions: a progress report. J Consult Clin Psychol. (2013) 81:196-205. doi: 10.1037/a0027085 
43. Qualtrics XM. Qualtrics Panels: Get Responses for Surveys \& Research. (2020). Available online at: https://www.qualtrics.com/online-sample/ (accessed June 26, 2020).

44. Budd EL. Correlates of health behaviors and outcomes among U.S. Latinx Adults. Harvard Dataverse. (2020) 1. doi: 10.7910/DVN/NABLZX

45. Tucker CM, Smith TM, Arthur TM, Wall W. Obesity and related chronic health conditions as predictors of motivation to engage in healthy eating behaviors among black adults. J Racial Ethn Heal Disparities. (2014) 1:1029. doi: 10.1007/s40615-014-0015-5

46. Smith TM, Tucker CM, Arthur TM, Wippold GM, Tran S. Frequency of visits to a health care provider, health promoting behaviors, and perceived health status among African American women. Women Heal. (2017) 57:58398. doi: 10.1080/03630242.2016.1178683

47. Centers for Disease Control and Prevention. Calculating BMI using the English System. (2014). Available online at: https://www.cdc.gov/nccdphp/dnpao/ growthcharts/training/bmiage/page5_2.html (accessed October 1, 2020).

48. Zea MC, Asner-Self KK, Birman D, Buki LP. The abbreviated multidimensional acculturation scale: Empirical validation with two Latino/Latina samples. Cult Divers Ethn Minor Psychol. (2003) 9:107-26. doi: 10.1037/1099-9809.9.2.107

49. Cervantes RC, Fisher DG, Padilla AM, Napper LE. The hispanic stress inventory version 2: improving the assessment of acculturation stress. Psychol Assess. (2016) 28:509-22. doi: 10.1037/pas0000200

50. Cervantes RC, Gattamorta KA, Berger-Cardoso J. Examining difference in immigration stress, acculturation stress and mental health outcomes in six Hispanic/Latino nativity and regional groups. J Immigr Minor Heal. (2019) 21:14-20. doi: 10.1007/s10903-018-0714-9

51. Cerin E, Saelens BE, Sallis JF, Frank LD. Neighborhood environment walkability scale: validity and development of a short form. Med Sci Sports Exerc. (2006) 38:1682-91. doi: 10.1249/01.mss.0000227639.83607.4d

52. Cerin E, Conway TL, Cain KL, Kerr J, De Bourdeaudhuij I, Owen N, et al. Sharing good NEWS across the world: developing comparable scores across. BMC Public Health. (2013) 13:309. doi: 10.1186/1471-2458-13-309

53. Martínez-Martínez OA, Ramírez-López A. Walkability and the built environment: validation of the Neighborhood Environment Walkability Scale (NEWS) for urban areas in Mexico. Qual Quant. (2018) 52:70318. doi: 10.1007/s11135-017-0483-x

54. Gravetter F, Wallnau L. Essentials of Statistics for the Behavioral Sciences. 8th ed. Wadsworth: Cengage Learning (2014).

55. Berry W, Feldman S. Multiple Regression in Practice (Quantitative Applications in the Social Sciences). Thousand Oaks, CA: SAGE Publications (1985). doi: 10.4135/9781412985208

56. Soto S, Arredondo EM, Villodas MT, Elder JP, Quintanar E, Madanat H. Depression and chronic health conditions among latinos: the role of social networks. J Immigr Minor Heal. (2016) 18:1292-300. doi: 10.1007/s10903-016-0378-2

57. Field AP. Discovering Statistics Using SPSS. 5th ed. Thousand Oaks, CA: SAGE Publications (2018).

58. Peng CYJ, Lee KL, Ingersoll GM. An introduction to logistic regression analysis and reporting. J Educ Res. (2002) 96:314. doi: 10.1080/00220670209598786

59. IBM Corp. IBM SPSS Statistics Version 26 for Windows. Armonk, NY: IBM Corp (2019). doi: 10.4324/9780429056765-3

60. R Core Team. R: A language and environment for statistical computing. (2014). Available online at: http://www.r-project.org/ (accessed October 9, 2020).

61. Long J. Comprehensive, User-Friendly Toolkit for Probing Interactions. (2019). Available online at: https://cran.r-project.org/package=interactions (accessed October 9, 2020).

62. Gong Y, Palmer S, Gallacher J, Marsden T, Fone D. A systematic review of the relationship between objective measurements of the urban environment and psychological distress. Environ Int. (2016) 96:4857. doi: 10.1016/j.envint.2016.08.019

63. Brown SC, Mason CA, Lombard JL, Martinez F, Plater-Zyberk E, Spokane $\mathrm{AR}$, et al. The relationship of built environment to perceived social support and psychological distress in hispanic elders: the role of "eyes on the street." $J$ Gerontol B Psychol Sci Soc Sci. (2009) 64:234-46. doi: 10.1093/geronb/gbn011

64. Perez LG, Carlson J, Slymen DJ, Patrick K, Kerr J, Godbole S, et al. Does the social environment moderate associations of the built environment with Latinas' objectively-measured neighborhood outdoor physical activity? Prev Med Rep. (2016) 4:551-7. doi: 10.1016/j.pmedr.2016.10.006
65. Centers for Disease Control and Prevention. How You Can Prevent Chronic Diseases. National Center for Chronic Disease Prevention and Health Promotion (2020). Available online at: https://www.cdc.gov/chronicdisease/ about/prevent/index.htm (accessed October 13, 2020).

66. Kerney MS, Harris BH, Jacome E, Parker L. Ten economic facts about crime and incarceration in the United States. Washington D.C. (2014). Available online at: https://www.brookings.edu/wp-content/uploads/2016/ 06/v8_THP_10CrimeFacts.pdf (accessed Oct. 14, 2020).

67. Pare PP, Felson R. Income inequality, poverty and crime across nations. $\mathrm{Br} J$ Sociol. (2014) 65:434-58. doi: 10.1111/1468-4446. 12083

68. Adkins A, Barillas-Longoria G, Nevárez Martínez D, Ingram M. Differences in social and physical dimensions of perceived walkability in Mexican American and non-hispanic white walking environments in Tucson, Arizona. J Transp Heal. (2019) 14:100585. doi: 10.1016/j.jth.2019. 100585

69. Lee DB, Eismanc AB, Stoddardd SA, Peckins MK, Goldstick JE, Hsieh H-F, et al. Racial discrimination and cortisol in African American emerging adults: the role of neighborhood racial composition. Cult Divers Ethn Minor Psychol. (2018) 24:521-9. doi: 10.1037/cdp0000217

70. Leyden KM. Social capital and the built environment: the importance of walkable neighborhoods. Am J Public Health. (2003) 93:1546-51. doi: 10.2105/AJPH.93.9.1546

71. Martinez SM, Ayala GX, Patrick K, Arredondo EM, Roesch S, Elder J. Associated pathways between neighborhood environment, community resource factors and leisure-time physical activity among MexicanAmerican adults in San Diego, CA. Am J Heal Promot. (2012) 26:281-8. doi: 10.4278/ajhp.100722-QUAN-249

72. Office of Minority Health. Profile: Hispanic/Latino Americans. U.S. Department of Health and Human Services (2017). Available online at: https://minorityhealth.hhs.gov/omh/browse.aspx?lvl=3\&lvlid=64 (accessed June 25, 2020).

73. Noe-Bustamante L, Flores A. Facts on Latinos in the U.S. Pew Research Center. (2019). Available online at: https://www.pewresearch.org/hispanic/fact-sheet/ latinos-in-the-u-s-fact-sheet/ (accessed June 25, 2020).

74. U.S. Census Bureau. 2018 Population Estimates by Age, Sex, Race and Hispanic Origin. U.S. Censuc Bureau (2018). Available online at: https://www.census. gov/newsroom/press-kits/2019/detailed-estimates.html (accessed June 29, 2020).

75. Livingston G, Minushkin S, Cohn D. Hispanics and Health Care in the United States. (2008). Available online at: https://www.pewresearch.org/ hispanic/2008/08/13/hispanics-and-health-care-in-the- united-statesaccess-information-and-knowledge/ (accessed June 30, 2020).

76. Centers for Disease Control and Prevention. Hispanics' Health in the United States. CDC Newsroom (2015). Available online at: https://www. cdc.gov/media/releases/2015/p0505-hispanic-health.html (accessed June 30, 2020).

77. Mazzuca J. U.S. Race Relations by Region: The West. GALLUP (2002). Available online at: https://news.gallup.com/poll/7213/us-race-relations-region-west. aspx (accessed July 11, 2020).

78. Shieh G. Detecting interaction effects in moderated multiple regression with continuous variables power and sample size considerations. Organ Res Methods. (2009) 12:510-28. doi: 10.1177/1094428108320370

79. Walter SL, Seibert SE, Goering D, O'Boyle EH. A tale of two sample sources: do results from online panel data and conventional data converge? J Bus Psychol. (2019) 34:425-52. doi: 10.1007/s10869-0189552-y

80. Cowie CC. Diabetes diagnosis and control: missed opportunities to improve health. Diabetes Care. (2019) 42:994-1004. doi: 10.2337/dci18-0047

Conflict of Interest: The authors declare that the research was conducted in the absence of any commercial or financial relationships that could be construed as a potential conflict of interest.

Copyright (C) 2021 Budd, Giuliani and Kelly. This is an open-access article distributed under the terms of the Creative Commons Attribution License (CC BY). The use, distribution or reproduction in other forums is permitted, provided the original author(s) and the copyright owner(s) are credited and that the original publication in this journal is cited, in accordance with accepted academic practice. No use, distribution or reproduction is permitted which does not comply with these terms. 